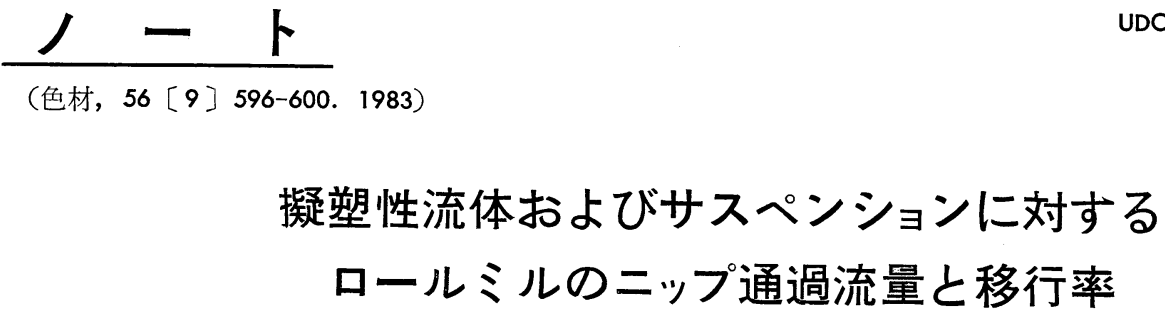

村上泰弘 ${ }^{*}$ - 広瀬 勉 ${ }^{* *}$-鄭 基市 ${ }^{*}$ - 秋本裕二***

\section{1. 緒言}

ロールミルは高粘度固液分散系に適したミルとして印 刷インキ，塗料，IC 用金属ペーストの分散などに広く 使われている。3本ロールミルの処理流量については, Zettlemoyer ${ }^{122)}$, Patton $^{3)}$, 釣谷4) らの報告があるが, ミルベースの流動性を考慮した検討はなされていない。 筆者らは 3 本ロールミルの処理流量を推算するため, 2 本ロール系でニュートン流体およびサスペンションを用 いてニップ通過流量と移行率を測定した5)。本報では擬 塑性流体和よび擬塑性流体をビヒクルとしたサスペンシ ョンについて実測した結果を報告する。

3 本ロールミルのマスバランスより，エプロンニップ クリアランスが適当な大きさでかきとりが十分に行われ ているとき, 処理流量 $Q$ は次式で求められる。

$$
Q=q_{f e} \cdot L_{e} \cdot C_{f} \cdot C_{a}
$$

ここで $q_{f e}$ は単位時間, 単位ロール有效長当たりのニッ プ通過流量 $q$ であり, 添字 $f e$ はフィードニップを通過 する流量であることを表わしている。 $L_{e}$ は口ール有効 長である。C は高速ロール側への移行率であり, $C_{f}, C_{a}$ はそれぞれフィードニップ，エプロンニップに拈ける高 速ロール側への移行率である。移行率はニュートン流体 のとき, 粘度, 速度, クリアランスによらず速度比 $n_{r}$ (高 速ロール速度， $u_{f} /$ 低速ロール速度， $u_{s}$ ) のみで (2) 式のように表わされる5)。

$$
C=\left(1+n_{r}^{-1.55}\right)^{-1}
$$

ニップ通過流量 $q$ はニュートン流体, サスペンションと

〔前報〕色材, 56, [9] 590-595（1983）

昭和 58.3.29 受理

* 九州大学工学部化学機械工学科 福岡市東区箱崎 6-10-1 (干812)

** 熊本大学工学部工業化学教室 熊本市黒髪 2-39-1（广860）

****昭栄化学工業(株)生産技術課 青梅市末広町 2-9-3 (
もに次式で表わされる。

$$
q=\lambda \cdot u_{m} \cdot h_{0}
$$

ここで, $u_{m}$ は平均周速度, $h_{0}$ はクリアランスである。 また，入はバンクの大きさによって変わる比例定数であ り $=$ ニートン流体の場合 $\lambda=1.30 \sim 1.45$ 程度である。

ニップ通過流量および移行率は 2 本ロールを使って求 められる量であるため, 本研究では 2 本ロール系で擬塑 性流体抢よびサスペンションについて実測した。

\section{2. 実 験 方 法}

実験には図-1に示すようなアクリル樹脂製 2 本ロー ル（直径 $9.9 \mathrm{~cm}$, 長さ $20 \mathrm{~cm}$, 表面仕上精度 $\pm 10 \sim 20$ $\mu \mathrm{m}$ ）を用いた。クリアランスは固定ロール側に 1 個, 可動ロール側に 2 個のダイアルゲージをロールに水平に 押しあて，操作中に測定した。

ニップ通過流量 $q$ はロールの下側で流体をかきとり， それを天科で受けて一定質量 $W$ に達する時間 $t$ から (4) 式上り求めた。

$$
q=W /\left(\rho \cdot t \cdot L_{e}\right)
$$

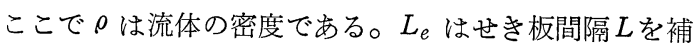
正した值を使った ${ }^{5)}$ 。測定はクリアランス $h_{0}=30 \sim 690$ $\mu \mathrm{m}$, 平均周速度 $u_{m}=0.2 \sim 0.43 \mathrm{~m} / \mathrm{s}$ の範囲で行った。

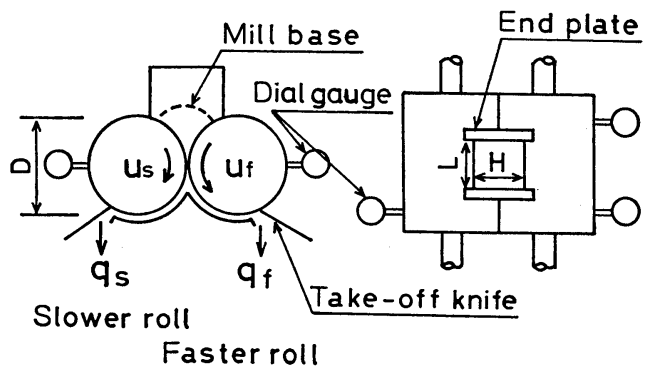
a) Side view
b) Plan

Fig. 1. Schematic diagrams of experimental apparatus 
Table 1. Power law constants $n$ and $K$ of CMC solutions

\begin{tabular}{c|c|c|c}
\hline & & $n$ & $K\left(\mathrm{~Pa} \cdot \mathrm{s}^{\mathrm{n}}\right)$ \\
\hline $\mathrm{CMC}-1$ & $\bigcirc$ & 0.91 & 6.78 \\
$\mathrm{CMC}-2$ & $\diamond$ & 0.84 & 7.65 \\
$\mathrm{CMC}-3$ & $\triangle \boldsymbol{\Delta} \Delta$ & 0.80 & 28.9 \\
$\mathrm{CMC}-4$ & $\odot$ & 0.70 & 19.6 \\
$\mathrm{CMC}-5$ & $\bigcirc$ & 0.61 & 47.4 \\
$\mathrm{CMC}-6$ & $\square \square$ & 0.61 & 53.7 \\
$\mathrm{CMC}-7$ & $\bigcirc$ & 0.31 & 234 \\
\hline
\end{tabular}

Viscosity was measured by cone-plate type viscometer at operating temperature.

またニップ通過流量は入が一定となる $H / h_{0}>100$ の 範囲で測定した。 $H$ はバンク幅 (図-1 参照)である。

高速ロールへの移行率 $C$ は高速側と低速側ロールで同 時にそれぞれ流体をかきとり，これを科量して求めた。 $h_{0}=144 \sim 607 \mu \mathrm{m}$ ，低速側 ロール 速度 $u_{s}=0.19 \sim 0.37$ $\mathrm{m} / \mathrm{s}$ ，速度比 $n_{r}=0.7 \sim 5.5$ の範囲で実験した。

流体は擬塑性流体として CMC 水溶液, サスペンショ ンとして CMC 水溶液に炭酸カルシウム抢よびアスベス トを分散させたものを用いた。サスペンションはあらか じめロールに数回通して，良く分散させたものを用い た。使用した $\mathrm{CMC}$ 水溶液の 流動性を指数法則 モデル （5）式で表わし，流動指数 $n$ 预よび定数 $K$ を求めた結 果を表-1 に示す。

$$
\tau=K \dot{\gamma}^{n}
$$

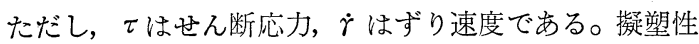
流体をビヒクルとしたサスペンションの流動性は小野木 ら ${ }^{6,7)}$ による修正 Casson 式（(6) 式）を使って良く表

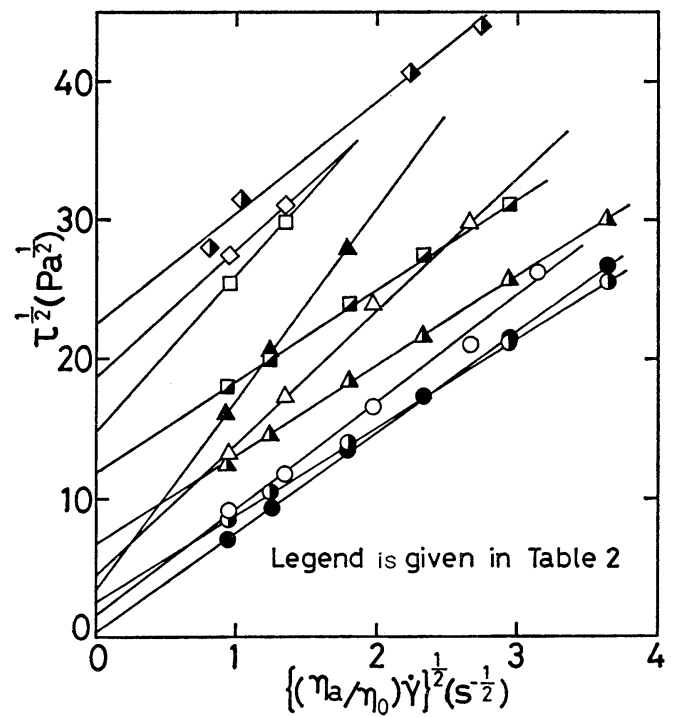

Fig. 2. Casson plots of suspensions

わされる。

$$
\tau^{1 / 2}=\tau_{c}^{1 / 2}+\left(\eta_{c} \cdot \dot{\gamma}\left(\eta_{a} / \eta_{0}\right)\right)^{1 / 2}
$$

ここで $\tau_{c}$ は降伏值, $\eta_{c}$ は修正 Casson 粘度, $\eta_{a}$ はビ ヒクルの見かけ粘度， $\eta_{0}$ はビヒクルのゼロせん断粘度 である。使用したサスペンションの流動性を測定し，

(6) 式でプロットした結果を図-2 に示す。ここで $\eta_{0}$ はC Cross の式多使って求めた。図-2 より, サスペン ションは良い直線性を示して叔り， $\eta_{c} ， \tau_{c}$ を求めるこ とができる。サスペンションの $\eta_{c}, \tau_{c}$ を求めた結果を 表-2 に示す。

\begin{tabular}{|c|c|c|c|c|c|c|c|}
\hline & & Vehicle & Pigment & $\begin{array}{l}\text { Volume } \\
\text { fraction }\end{array}$ & $\tau_{\mathrm{c}}(\mathrm{Pa})$ & $\eta_{c}(\mathrm{~Pa} \cdot \mathrm{s})$ & $N_{\mathrm{B}}(-)$ \\
\hline CA-1 & - & CMC-5 & Asbestos & 0.07 & 6.32 & 40.4 & $2.51 \times 10^{-4}$ \\
\hline CA-2 & $\Delta$ & " & " & 0.14 & 44.7 & 41.4 & $1.73 \times 10^{-3}$ \\
\hline $\mathrm{CA}-3$ & $\square$ & $" 1$ & $"$ & 0.19 & 139 & 44.8 & $4.96 \times 10^{-3}$ \\
\hline $\mathrm{CA}-4$ & $\downarrow$ & $" \prime$ & $"$ & 0.25 & 502 & 63.9 & $1.26 \times 10^{-2}$ \\
\hline $\mathrm{CC}-1$ & 0 & $\mathrm{CMC}-4$ & Chalk & 0.25 & 2.79 & 56.9 & $7.87 \times 10^{-5}$ \\
\hline $\mathrm{CC}-2$ & $\triangle$ & " & " & 0.35 & 18.8 & 92.2 & $3.27 \times 10^{-4}$ \\
\hline $\mathrm{CC}-3$ & $\square$ & $"$ & $"$ & 0.42 & 220 & 123 & $2.86 \times 10^{-3}$ \\
\hline $\mathrm{CC}-4$ & $\diamond$ & " & " & 0.48 & 344 & 84.6 & $6.51 \times 10^{-3}$ \\
\hline $\mathrm{CC}-5$ & 0 & CMC-5 & $"$ & 0.15 & 0.124 & 51.9 & $3.83 \times 10^{-6}$ \\
\hline $\mathrm{CC}-6$ & $\Delta$ & " & $"$ & 0.35 & 11.3 & 188 & $9.64 \times 10^{-5}$ \\
\hline
\end{tabular}

Table 2. Pigment volume fractions and flow properties of suspensions

Viscosity was measured by cone-plate type viscometer at operating temperature except CC-4 and CA -4 at $30^{\circ} \mathrm{C}$.

Bingham number $N_{\mathrm{B}}=\tau_{\mathrm{c}} h_{0} / \eta_{\mathrm{c}} \cdot u$, where $h_{0}=300 \mu \mathrm{m}$ and $u=0.187 \mathrm{~m} / \mathrm{s}$. $\eta_{\mathrm{c}}$ is viscosity of modified Casson equation. 


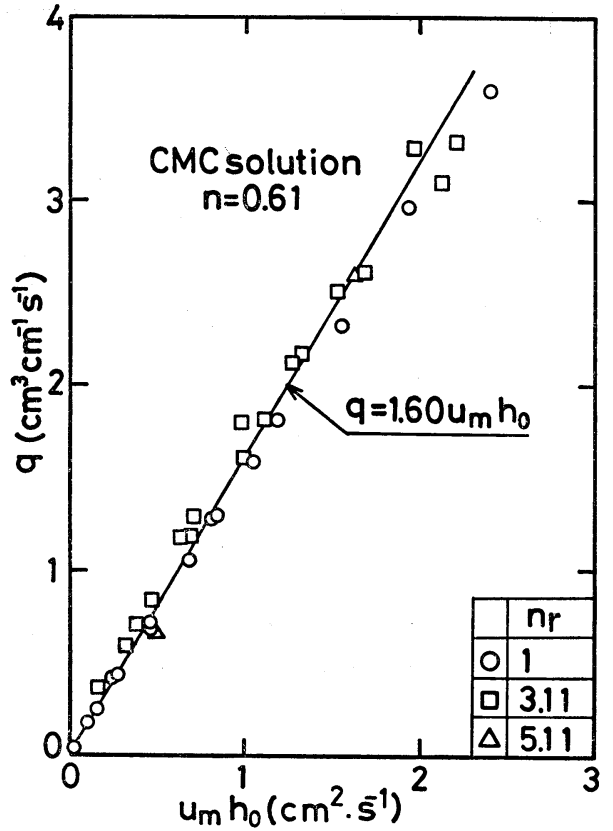

Fig. 3. Total flux through the nip for a pseudoplastic fluid

Table 3 .

\begin{tabular}{l|l|l|l|l}
\hline$n$ & 1.0 & 0.80 & 0.61 & 0.31 \\
\hline$\lambda$ & 1.44 & 1.48 & 1.60 & 1.62 \\
\hline$\lambda^{*}$ & 1.226 & 1.231 & 1.239 & 1.259 \\
\hline
\end{tabular}

* calculated by Brazinsky et $\mathrm{al}^{9}$.

\section{3. 結果と考察}

\section{1 ニップ通過流量}

CMC-6 を使い, ニップ通過流量を測定した結果を図 -3に示す。図-3 より非ニュートン流体についても (3) 式が成立し， $\lambda$ はニュートン流体の場合より大きなこと がわかる。流動指数 $n$ の異なる CMC-3，7 を使い $\lambda$ を 測定した結果をあわせて表-3 に示した。表-3にはBrazinsky $ら^{9)}$ による計算值もあわせて示した。表-3 より， $n$ が小さくなり非ニュートン性が顕著になれば $\lambda$ が大き くなっていることがわかるが，その傾向は Brazinsky らの計算結果と同じである。

\section{2 移行率}

高速ロールに移る流量を $q_{f}$, 低速ロールに移る流量 を $q_{s}$ とすると, 高速ロールへの移行率 $C$ と流量比 $q_{f} l$ $q_{s}$ との間には次の関係がある。

$$
C=q_{f} /\left(q_{f}+q_{s}\right)=\left(1+\left(q_{f} / q_{s}\right)^{-1}\right)^{-1}
$$

ニュートン流体の場合, 流量比は速度比 $n_{r}$ のみの関数

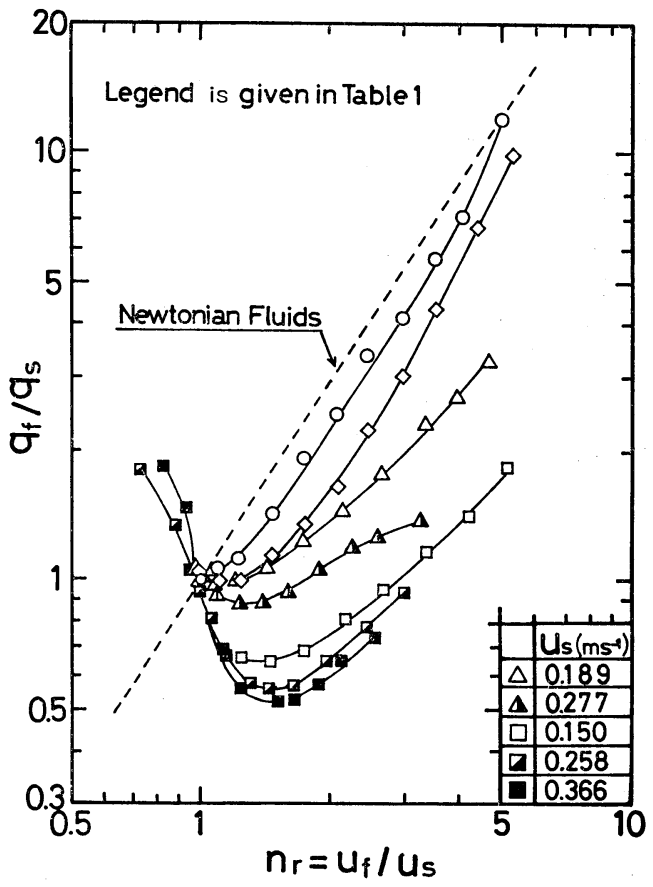

Fig. 4. Dependence of flux ratio $q_{\mathrm{f}} / q_{\mathrm{s}}$ on roll speed ratio $n_{\mathbf{r}}$ for pseudoplastic fluids

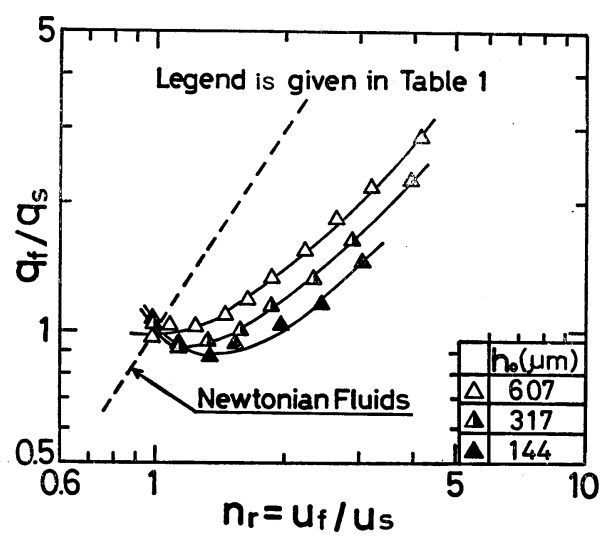

Fig. 5. Dependence of flux ratio $q_{\mathrm{f}} / q_{\mathrm{s}}$ on roll speed ratio $n_{\mathrm{r}}$ and clearance $h_{0}$ for pseudoplastic fluid

となり次式で表わせる5)。

$$
q_{f} / q_{s}=n_{r}^{1.55}
$$

CMC-1〜3， 6 を使い，流量比 $q_{f} / q_{s}$ を測定した結果 を図-4 に示す。図-4 より, ニュートン流体の場合と異 なって，低速ロール側に多く移行しており，また（8） 式のような単純な指数関係にないことがわかる。流動指 数 $n$ が小さくなり, 非ニュートン性が顕著になるに従っ て低速側ロールにより多く移行している。図-4には 


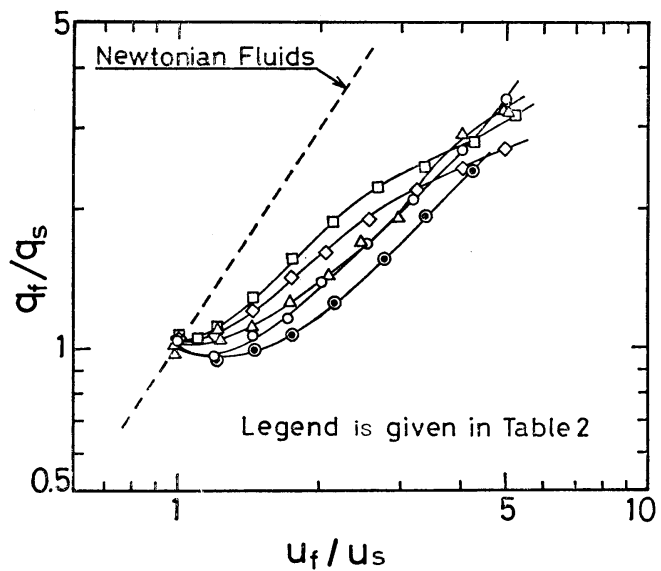

Fig. 6. Dependence of flux ratio $q_{\mathrm{f}} / q_{\mathrm{s}}$ on roll speed ratio $u_{\mathrm{f}} / u_{\mathrm{s}}$ for chalk suspensions

CMC-3，6 を使い低速側ロール速度 $u_{s}$ を変えた結果 もあわせて示した。低速側ロール速度が大きくなるに従 って，低速ロール側により多く移行する傾向がわかる。 図-4 はすべてクリアランスを約 $300 \mu \mathrm{m}$ にして測定し た結果であるが， CMC-3 を使いクリアランスを変克て 測定した結果を図-5 に示す。図-5より，クリアランス が狭い汪ど低速ロール側に多く移行することがわかる。 これらより,非ニュートン性が顕著になり,ニップにおけ るせん断速度が大きくなるほど低速ロール側に多く移行 していることがわかる。さらに非ニュートン性が顕著な CMC-7 を使って湘定した結果, 等速回転でも一方の口 ールに 10 倍以上の厚さの膜ができ，これがもら一方の ロールに移りあったり，速度比が大きくなるにつれてロ ール上の膜が不安定になり破れたようになるなどの異常 流動が観察された。

炭酸カルシウムを CMC-4 に分散させたサスペンショ ン CC-1〜4 の流量比を測定した結果を図-6に示す。 ビヒクルである CMC-4 だけの時よりも，顔料濃度が高 くなるにつれて高速ロール側に多く移行するようになっ ている。しかし, 顔料濃度が高く, 速度比が大きくなる と再び流量比は小さくなる傾向がみられる。CMC-5に 炭酸カルシウム拈よびアスベストを分散したサスペンシ ョン CC-5〜6, CA-1〜4 の測定結果を図-7 に示す。図 -7 より，炭酸カルシウム分散系は $\mathrm{CMC}$ ビヒクルのみ の時よりも流量比は大きくなり，アスベスト分散系では 流量比は小さくなっており，傾向が全く違らことがわか る。また，アスベスト分散系のなかでも CA-3，4 のよ らに体積分率が高くなり, 表-2 に示した Bingham 数 $N_{B}$ が $10^{-3}$ 以上のオーダーになると複雑な挙動を示し, 速 度比 4 以上でニュートン流体の流量比をこえている。

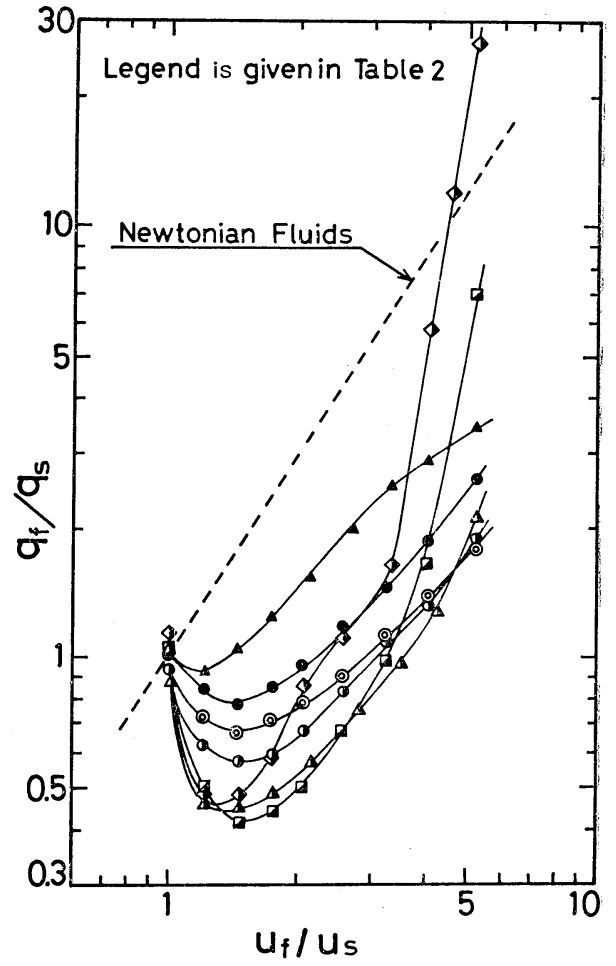

Fig. 7. Dependence of flux ratio $q_{\mathrm{f}} / q_{\mathrm{s}}$ on roll speed ratio $u_{\mathrm{f}} / u_{\mathrm{s}}$ for chalk and asbestos suspensions

アスベスト分散系と炭酸カルシウム分散系の流量比の 違いは，分散系の粘弾性が関与していると思われるた め, 動的粘弾性を二重円筒型レオメーターで測定した。 その結果，顔料濃度が高くなれば動的弾性率は高くな り，緩和時間は減少していくという傾向はアスベスト， 炭酸カルシウム，いずれの分散系についても同じであ り，図-7 の挙動の違いは説明できなかった。

\section{4. 結言}

2 本ロールを使って，擬塑性流体および擬塑性流体を ビヒクルとしたサスペンションのニップ通過流量と移行 率を実測した。ニップ通過流量は擬塑性流体の場合も （3）式で表わせ, 比例定数入は非ニュートン性が顕著 になるにつれて大きくなった。流量比は, ニュートン流 体と異なり速度比と単純な指数関係になく, 非ニュート ン性が顕著になるにつれて低速ロール側に多く移行する 傾向がみられた。サスペンションの場合は顔料, 顔料濃 度によってさまざまな挙動を示したが，その挙動の解明 は今後の課題である。

〔謝辞】本研究を行うにあたり，実験に助力をいただい 
た平田和彦君（現三井造船(株)），川口恭司君，天田次 雄君に心から感謝いたします。また，実験に対して御援 助いただいた芦沢鉄工(株) 楠 真澄常務，土師陽子主 任に深く感謝いたします。

\section{参考文献}

1) J. H. Taylor, Jr., A. C. Zettlemoyer : Paint Manufacture, 8, 299 (1957)

2) A. C. Zettlemoyer, J. H. Taylor, Jr.: Off. Dig., 5, 648 (1960)

3) T. C. Patton: "Paint Flow and Pigment Dis- persion”, Interscience Pub. New York (1966)

4）釣谷泰一：色材, 43, 54 (1970)

5）村上泰弘，広瀬 勉，鄭 基市：色材，56[9] 590 (1983)

6) T. Matsumoto, A. Takashima, T. Masuda, S. Onogi : Trans. Soc. Rheology, 14, 4, 617 (1970)

7）小野木重治，松本孝芳：色材，43，389（1970）

8) M. M. Cross : J. Colloid Science, 20, 417 (1965)

9) I. Brazinsky, H. F. Cosway, C. F. Valle, Jr., R. C. Jones, V.Story : J. Appl. Poly. Sci., 14, 2771 (1970)

\title{
Flux and Flux Ratio through the Nip of Roll Mill for Pseudoplastic Fluids and Suspensions
}

\author{
Yasuhiro Murakami*, Tsutomu Hirose**, Gishi Chung* \\ and Yuji Акімото*** \\ * Department of Chemical Engineering, Kyusyu University-36, 6-10-1, \\ Hakozaki, Higashi-ku, Fukuoka 812, Japan \\ ** Department of Industrial Chemistry, Kumamoto University, 2-39-1, \\ Kurokami, Kumamoto 860, Japan \\ *** Shoei Chemical Industry Co., Ltd. 2-9-3, Suehiro, Ohme, Tokyo 198, \\ Japan
}

\begin{abstract}
In order to predict the production rate of a three-roll mill, the total flux through the nip, $q$ and flux ratio, $q_{f} / q_{s}$ for pseudoplastic fluids (CMC solutions) and suspensions (pigment:chalk, asbestos) were investigated in a two-roll system.

For pseudoplastic fluids, $q$ is given by $q=\lambda \cdot u_{m} \cdot h_{0}$ where $u_{m}$ is averaged roll speed and $h_{0}$ is clearance. Proportional constant $\lambda$ was larger than that of Newtonian fluid and increased with flow index (power law model) decreased. Flux ratio decreased with flow index decreased and simple correlation as Newtonian fluid could not be found for pseudoplastic fluids and suspensions.
\end{abstract}

